\title{
Erratum to: Providing Patients with Implantable Cardiac Device Data through a Personal Health Record: A Qualitative Study
}

\author{
Carly N. Daley ${ }^{1,2}$ Elizabeth M. Chen ${ }^{1,3}$ Amelia E. Roebuck ${ }^{1}$ Romisa Rohani Ghahari ${ }^{1}$ Areej F. Sami ${ }^{4}$ \\ Cayla G. Skaggs ${ }^{1}$ Maria D. Carpenter ${ }^{1}$ Michael J. Mirro ${ }^{1,4}$ Tammy R. Toscos ${ }^{1,2}$
}

${ }^{1}$ Department of Research Informatics, Parkview Health System, Mirro Center for Research and Innovation, Fort Wayne, Indiana, United States

2 Department of BioHealth Informatics, Indiana University School of Informatics and Computing, Indianapolis, Indiana, United States

${ }^{3}$ Marian University College of Osteopathic Medicine, Indianapolis, Indiana, United States

${ }^{4}$ Department of Medicine, Indiana University School of Medicine, Indianapolis, Indiana, United States

Appl Clin Inform 2017;8:e1.
Address for correspondence Carly N. Daley, MS, Parkview Mirro Center for Research and Innovation, 10622 Parkview Plaza Dr., Fort Wayne, IN 46845, United States (e-mail: carly.daley@parkview.com).

The authors would like to make modifications to the participants' age range in the above article in Applied Clinical Informatics, Volume 8, Number 4, 2017 (DOI: 10.4338/ACI-201706-RA-0090).

1. In Abstract, Results, sentence 1, "Participants were $\mathbf{3 6}$ to 90 years old, mean age (SD) of 67 (14) years, predominately male (76\%), and white (95\%)" should read as "Participants were 36 to 86 years old, mean age (SD) of 67 (14) years, predominately male (76\%), and white (95\%)."

2. In Results, para 1, sentence 1, "Participants' age ranged from $\mathbf{3 6}$ to $\mathbf{9 0}$ years, with a mean (SD) of 67 (14) years, and were predominately male (76\%)" should read as "Participants' age ranged from 36 to 86 years, with a mean (SD) of 67 (14) years, and were predominately male (76\%)."

3. In Meaningful Applications for the ICD Data Summary, para 1, sentence 5, "As the participants in this study ranged in age between $\mathbf{3 6}$ and 90 years, it is worth noting that the interest in more complex data tracking seemed to be more common among younger participants" should read as "As the participants in this study ranged in age between $\mathbf{3 6}$ and 86 years, it is worth noting that the interest in more complex data tracking seemed to be more common among younger participants." 